\title{
The Prevalence and Pattern of Cannabis Use Among Patients Attending a Methadone Treatment Clinic in Nairobi, Kenya
}

Elizabeth Wambui Ngarachu ( $\square$ wambui.liz@gmail.com )

Mathari National Teaching \& Referral Hospital Department of Psychiatry https://orcid.org/0000-00024680-8801

Sarah Kanana Kiburi

Mbagathi Hospital Department of Psychiatry

Frederick R. Owiti

University of Nairobi College of Health Sciences Department of Psychiatry

Rachel Kangethe

University of Nairobi College of Health Sciences Department of Psychiatry

\section{Research Article}

Keywords: Pattern of cannabis use, prevalence of cannabis use, opioid use disorder, methadone maintenance clinic, Kenya

Posted Date: September 28th, 2021

DOI: https://doi.org/10.21203/rs.3.rs-927162/v1

License: (c) (1) This work is licensed under a Creative Commons Attribution 4.0 International License. Read Full License 


\section{THE PREVALENCE AND PATTERN OF CANNABIS USE AMONG PATIENTS ATTENDING A METHADONE TREATMENT CLINIC IN NAIROBI, KENYA}

Elizabeth Wambui Ngarachu*, Sarah Kanana Kiburi, Rachel Kangethe, Frederick Owiti

Elizabeth Wambui Ngarachu, Department of Psychiatry, Mathari National Teaching and Referral Hospital, Nairobi Kenya, email wambui.liz@gmail.com (Corresponding author)

Sarah Kanana Kiburi, Department of Psychiatry, Mbagathi Hospital, Nairobi, Kenya, emailsarahkiburi@gmail.com

Frederick R. Owiti, Department of Psychiatry, University of Nairobi, Kenya, email f.owiti89@gmail.com

Rachel Kangethe, Department of Psychiatry, University of Nairobi, Kenya, email drkangethe@gmail.com 


\begin{abstract}
Background: Cannabis use during methadone treatment may negatively impact treatment outcomes. The aim of this study was to determine the prevalence and pattern of cannabis use among patients attending a methadone treatment clinic in Nairobi, Kenya.
\end{abstract}

Methods: This was a retrospective study of 874 patients on methadone therapy at a methadone maintenance treatment clinic in Nairobi, Kenya from December 2014 to November 2018. Data on sociodemographic characteristics and drug use patterns based on urine drug screens was collected from patient files. Data was analyzed using Statistical Package for the Social Sciences (SPSS) for windows version 23.0.

Results: Prevalence of cannabis use was $85.8 \%(95 \%$ CI, $83.3-88.0)$ at baseline and $62.7 \%(95 \%$ CI, $59.5-65.8)$ during follow up. A pattern of polysubstance use was observed where opioids, cannabis and benzodiazepines were the most commonly used drugs. The mean age of the patients was 35.3 (SD 9.0) years with majority being male, unemployed (76\%), had primary level of education (51.4\%) and divorced or separated (48.5\%). Cannabis use was associated with dropping out of treatment $(\mathrm{p}=0.001)$ and university education was associated with reduced risk for cannabis use $\mathrm{OR}=0.1(95 \%$ CI, 0.02-0.8, $\mathrm{p}=0.031)$.

Conclusion: Cannabis use is prevalent among patients attending a methadone treatment clinic in Kenya and is associated with dropping out of treatment. There is a need for targeted interventions to address the problem of cannabis use during methadone maintenance treatment in Nairobi, Kenya.

Key words: Pattern of cannabis use, prevalence of cannabis use, opioid use disorder, methadone maintenance clinic, Kenya 


\section{Background}

Cannabis is the most common substance used with a global prevalence of $4 \%$ among those aged 15-64 years and a trend of increasing use in recent years (1). Cannabis use causes adverse health outcomes including negative impact on neurodevelopment, increased risk of addiction and other substance use, cognitive impairment, poor education achievement $(2,3)$ and increased risk for psychiatry illness such as psychosis, depressive and anxiety disorders $(4,5)$. Whilst in recent years cannabis products have become more potent, majority of young people do not consider cannabis as harmful a trend that may lead to increased risk of negative impact from cannabis use (1).

Opioid use is prevalent with past-year prevalence of $1.2 \%$ globally with a trend of increasing use in Africa $(1,6)$. In Kenya, prevalence of opioid use is $0.3 \%$ in the general population aged 15-65 years and $1.6 \%$ among secondary school students $(7,8)$, while among inpatients with substance use disorders the prevalence is higher (9). Opioid use disorder refers to problematic use of opioids that leads to significant distress and impairment including physical, social and occupational dysfunction (10). Treatment for opioid use disorder involves pharmacotherapy with opioid substitution treatment (OST) in conjunction with psychosocial interventions. Among the OST medications methadone is the most commonly used and is effective in improving outcomes among patients with opioid use disorder (11-14).

Prevalence of cannabis use in patients on methadone maintenance treatment (MMT) is common and higher than prevalence in the general population (15). A systematic review of 23 studies reported cannabis use prevalence of $11.2 \%-78.6 \%$ among patients on MMT (15) while another review of 41 studies in different OST programs, the median prevalence at baseline was $23 \%$, median cumulative prevalence throughout treatment was $58 \%$ and median prevalence of frequent use at $18.5 \%(16)$. There is geographical differences as shown in studies in different 
regions. For example in Canada, the prevalence ranged from $23.1 \%$ to $59.7 \%$ (17-19); in South Africa, prevalence of $87.3 \%$ at baseline and $73 \%$ during follow up (20); while two studies in China and Malaysia reported very low prevalence of $0.8 \%$ and $0.4 \%$, respectively $(21,22)$. Gender difference in cannabis use has been shown with prevalence of use being higher in males compared to females $(18,19)$.

Cannabis use during MMT is associated with negative effects such as increased risk of dropping out of treatment, continued illicit opioid and other substance use, poor family relationships and psychosocial functioning, increased rate of incarceration, and physical and psychological health problems $(15,17,18,23-25)$. In contrast, some studies report on benefits of cannabis use during MMT including less opioid use, reduction in opioid withdrawal symptoms $(26,27)$, better retention in treatment (28) with some authors suggesting role for cannabis in opioid use disorder treatment $(29,30)$. Furthermore gender differences in outcomes have been reported with one study reporting that only females using cannabis at baseline and males with heavy cannabis use had higher risk (17) while in another study cannabis use was associated with increased opioid use in females only (18). Whilst overall findings in two systematic reviews did not suggest cannabis use during OST to impact on the treatment outcomes $(15,16)$, sub-group analysis of data in one review showed that cannabis use during MMT was associated with poor retention for studies in United States of America with an opposite effect for studies in Israel (15).

In sub-Saharan Africa, MMT services are offered in Kenya and seven other countries hence there is limited research on cannabis use among patients with opioid use disorder on MMT in Africa $(31,32)$. Regionally in Tanzania, two studies have been conducted among patients on MMT but do not report on prevalence of cannabis use in part of the outcomes $(33,34)$. In Kenya, MMT is offered in government-funded clinics since December 2014 with current number of 
clinics being eight in several regions in the country (35). To the authors' knowledge, no study has been done to assess cannabis use among patients with opioid use disorder on MMT. Therefore, the objective of this study was to examine the prevalence and pattern of cannabis use and their association with sociodemographic characteristics among patients receiving MMT.

\section{Methods}

\section{Study design}

This was a cross-sectional study that involved retrospective abstraction of data from patient files in the methadone maintenance treatment clinic.

\section{Study setting}

The study was conducted at the MMT clinic in Mathari National Teaching \& Referral Hospital (MNTRH) which was the first urban, publicly funded and university-sponsored MMT clinic located in Nairobi $(35,36)$. In addition to MMT, other services at the clinic include treatment for comorbid disorders such as HIV, tuberculosis, sexually transmitted diseases and psychiatric illness. The eligibility criteria for MMT initiation are: individuals presenting with opioid use disorder, above 18 years of age and testing positive for opiates through urine drug screening. The patients attend the MMT clinic daily to receive their prescribed methadone dose which is given as directly observed treatment.

\section{Study population}

The study population was patients on methadone treatment at MNTRH MMT clinic.

\section{Sample size and sampling procedure}

The targeted sample size was files of all patients who were enrolled into the MMT clinic from December 2014 to November 2018 at MNTRH. The patients enrolled within the study period were 984. The patients' files at the MMT clinic had an outpatient number that helped in locating 
the files from the shelves. The outpatient number was a distinct number given to each patient on enrollment into the MMT clinic. The standard procedure for MMT enrollment and induction was baseline urine drug screen tests at intake. During the methadone maintenance therapy, random urine drug screens were performed every three months and the results were attached in the patient files. We excluded $11.2 \%(\mathrm{n}=110)$ of patients who had missing information on bio data and urine drug screens. Figure 1 shows the flow chart and the final number of patients was 874 .

Figure 1: Flow chart of sample size and sampling procedure

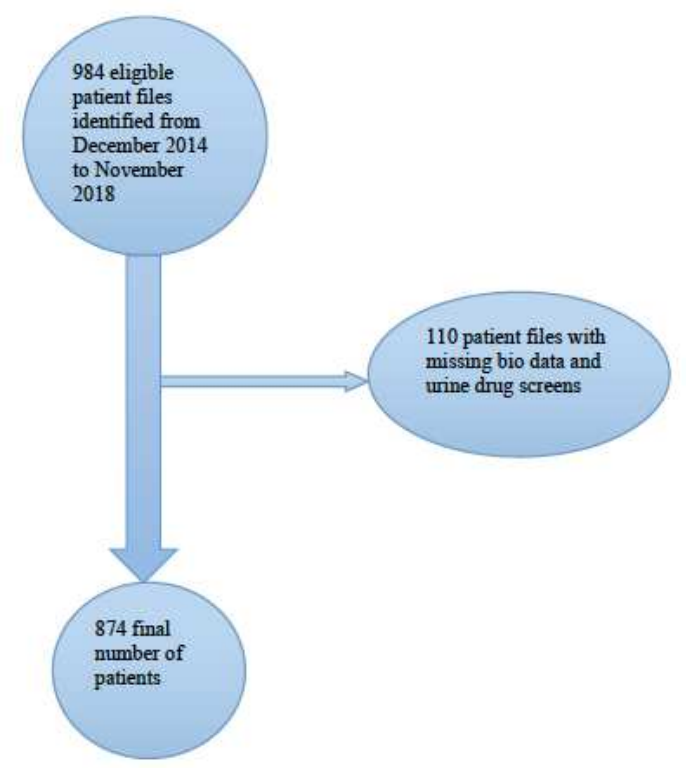

\section{Inclusion and exclusion criteria}

The inclusion criteria were patients (1) on methadone treatment in the MMT clinic at MNTRH (2) who were enrolled and initiated methadone therapy within the study period (December 2014 to November 2018) (3) who had urine drug screen results. The exclusion criteria were patients (1) not enrolled within the study period and (2) those with missing information on biodata and urine drug screens. 


\section{Data collection procedures}

A data collection form was used to document data retrieved from the patient files at the records department in the MMT clinic. The data collected included date of enrollment, age, gender, education level, marital status, occupation and urine drug screen results. A pilot study was carried out to pretest the tool prior to the study to ensure validity and reliability. This was done using a sample of 20 patient files at the MMT clinic. The patient sociodemographic and urine drug screen results were retrieved from the selected files that met the inclusion criteria then documented in the data collection forms. A copy of the data abstraction tool used is attached as supplementary material.

\section{Data management}

Data entry and analysis was done using Statistical Package for the Social Sciences (SPSS) for windows version 23.0. This study utilized univariate and bivariate analysis. In univariate analysis, demographic data was presented by frequency and proportions. Distribution of data was shown by central tendency measurements. In bivariate analysis, chi square and Fisher's exact test were used to represent the nature of cannabis use among methadone patients and test the significance of the association between the variables. The threshold for statistical significance was set at $p \leq 0.05$. The results were presented using narratives, tables, charts and graphs. 


\section{Results}

Sociodemographic characteristics of patients attending a methadone maintenance treatment clinic in Nairobi, Kenya

Table 1 is a summary of the sociodemographic characteristics of patients attending a methadone maintenance treatment clinic in Nairobi, Kenya. The mean age of the patients was 35.3 (SD 9.0) years, while the median age was 35.0 (IQR 29-41) years. The minimum age was 18 years while the maximum age was 81 years. Majority $(88.2 \%)$ were males, $51.4 \%$ had primary education, and $76 \%$ were unemployed.

Table 1: Sociodemographic characteristics of patients

\begin{tabular}{lcc}
\hline Age (Years) & Frequency $(\mathbf{n}=\mathbf{8 7 4})$ & Percentage (\%) \\
\hline $18-27$ & 178 & 20.4 \\
$28-37$ & 354 & 40.5 \\
$38-47$ & 271 & 31.0 \\
$48-57$ & 56 & 6.4 \\
$58-67$ & 12 & 1.4 \\
$68+$ & 3 & 0.3 \\
\hline Gender & & \\
\hline Male & 771 & 11.8 \\
Female & 103 & \\
\hline Education & & 51.4 \\
\hline Primary & 449 & 38.0 \\
Secondary & 332 & 7.8 \\
Tertiary & 68 & 1.1 \\
University & 10 & 1.7 \\
None & 15 & 23.3 \\
\hline Marital status & & 26.0 \\
\hline Single & 227 & 23.3 \\
Married & 204 &
\end{tabular}




\begin{tabular}{lcc} 
Divorced/Separated & 424 & 48.5 \\
Widowed & 19 & 2.2 \\
\hline Employment & & 17.6 \\
\hline Employed & 154 & 6.4 \\
Business & 56 & 76.0 \\
Unemployed & 664 & \\
\hline
\end{tabular}

Prevalence of cannabis use at baseline among patients attending a methadone maintenance treatment clinic in Nairobi, Kenya

The prevalence of cannabis use at baseline among patients attending a methadone maintenance treatment clinic in Nairobi, Kenya was $85.8 \%(95 \%$ CI, $83.3-88.0)$.

Pattern of cannabis use at baseline among patients attending a methadone maintenance treatment clinic in Nairobi, Kenya

The baseline urine drug screens carried out at intake revealed polysubstance use whereby substances used were opioids, cannabis, benzodiazepines, cocaine, barbiturates and amphetamines. This is shown in table 2 .

Prevalence of cannabis use at repeat urine drug screen among patients attending a methadone maintenance treatment clinic in Nairobi, Kenya

The prevalence of cannabis use of patients attending a methadone maintenance treatment clinic in Nairobi, Kenya during follow up as shown by repeat urine drug screen was $62.7 \%$ (95\% CI, $59.5-65.8)$. 
Pattern of cannabis use at repeat urine drug screen among patients attending a methadone maintenance treatment clinic in Nairobi, Kenya

The repeat urine drug screens carried out on patients attending the methadone program revealed polysubstance use. Table 2 shows the substances used were opioids, cannabis, benzodiazepines, cocaine and barbiturates.

Table 2: Pattern of cannabis use at baseline and repeat urine drug screen

Pattern of cannabis use at baseline

Substance Frequency Percent

$(n=874)$

Cannabis and Opioids 359

41.1

Cannabis, Benzodiazepines and Opioids 281

Cannabis, Barbiturates, Benzodiazepines and Opioids 44

Cannabis, Cocaine, Barbiturates, Benzodiazepines and Opioids 20

Cannabis, Barbiturates, and Opioids 17

Cannabis, Cocaine, Benzodiazepines and Opioids 15

Cannabis, Cocaine and Opioids 10

Cannabis, Cocaine, Barbiturates and Opioids 2

0.2

Cannabis, Cocaine, Benzodiazepines and Amphetamines 1

Cannabis, Opioids and Amphetamines 1

0.1

No cannabis use

124

Pattern of cannabis use at repeat urine drug screen

\begin{tabular}{lcc}
\hline Substance & $\begin{array}{c}\text { Frequency } \\
(\boldsymbol{n = 8 7 4 )}\end{array}$ & $\begin{array}{c}\text { Percent } \\
(\mathbf{\%})\end{array}$ \\
\hline Cannabis only & 338 & 38.7 \\
Cannabis and Opioids & 167 & 19.1 \\
Cannabis, Benzodiazepines and Opioids & 25 & 2.9 \\
Cannabis and Benzodiazepines & 16 & 1.8 \\
Cannabis and Cocaine & 1 & 0.1 \\
Cannabis, Barbiturates, Benzodiazepines, and Opioids & 1 & 0.1 \\
No cannabis use & 326 & 37.3 \\
\hline
\end{tabular}




\section{Comparison between cannabis use at baseline and repeat urine drug screen}

Table 3 shows the distribution of cannabis use at baseline against cannabis use at repeat urine drug screen whereby $64.7 \%(n=485)$ of those using cannabis at baseline continued to use cannabis while $50.8 \%(n=63)$ of those not using cannabis at baseline had initiated cannabis use during follow up. A McNemar's test revealed a statistical difference between the use of cannabis at baseline and at the repeat urine drug screen $(\mathrm{p}<0.001)$.

Table 3: Comparison between cannabis use at baseline and repeat urine drug screen

\begin{tabular}{lccc}
\hline & \multicolumn{3}{c}{ Cannabis use at repeat urine drug screen } \\
\hline $\begin{array}{l}\text { Cannabis use at } \\
\text { baseline }\end{array}$ & Yes & $485(64.7)$ & No \\
& & & $265(35.3)$ \\
& No & $63(50.8)$ & $61(49.2)$ \\
\hline
\end{tabular}

Pattern of cannabis use by gender among patients attending a methadone maintenance treatment clinic in Nairobi, Kenya

During follow up $55.9 \%$ of males and $52.4 \%$ of females had continued cannabis use while among those initiating cannabis use during follow up, females were more likely than males to initiate cannabis use $(9.7 \%$ versus $6.9 \%)$ but this difference was not statistically significant. This is summarised in table 4 .

Table 4: Pattern of cannabis use by gender

\begin{tabular}{lcccc}
\hline Pattern & Male (\%) & Female (\%) & Total (\%) & p-value \\
\hline Continued cannabis use & $431(55.9)$ & $54(52.4)$ & $485(55.5)$ & 0.505 \\
New cannabis users & $53(6.9)$ & $10(9.7)$ & $63(7.2)$ & 0.296 \\
Never used cannabis & $52(6.7)$ & $9(8.7)$ & $61(7.0)$ & 0.456 \\
Stopped cannabis use & $235(30.5)$ & $30(29.1)$ & $265(30.3)$ & 0.779 \\
Total & $\mathbf{7 7 1 ( 1 0 0 . 0 )}$ & $\mathbf{1 0 3 ( 1 0 0 . 0 )}$ & $\mathbf{8 7 4 ( 1 0 0 . 0 )}$ & \\
\hline
\end{tabular}




\section{Pattern of cannabis use by enrolment status}

Of the 874 patients at baseline, 182 were lost to follow up, of which, $83.5 \%(n=152)$ used cannabis at baseline and $69.2 \%(n=126)$ had cannabis use during follow up. A sub-analysis of only this group on their cannabis use status at baseline and repeat UDS using McNemar's test revealed a statistically significant difference $(\mathrm{p}=0.001)$. Table 5 summarizes the pattern of cannabis use based on enrollment status.

Table 5: Pattern of cannabis use by enrollment status of patients

Pattern of cannabis use

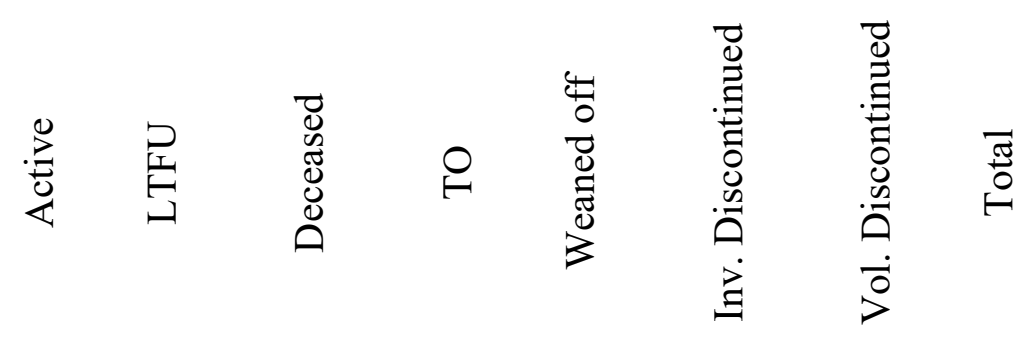

\begin{tabular}{lcccccccc}
\hline Continued cannabis use & 344 & 108 & 9 & 5 & 12 & 3 & 4 & 496 \\
New cannabis users & 40 & 18 & 1 & 1 & 3 & 0 & 0 & 65 \\
Never used cannabis & 41 & 12 & 3 & 0 & 4 & 1 & 0 & 64 \\
Stopped cannabis use & 172 & 44 & 9 & 2 & 35 & 0 & 3 & 269 \\
Total & $\mathbf{5 9 7}$ & $\mathbf{1 8 2}$ & $\mathbf{2 2}$ & $\mathbf{8}$ & $\mathbf{5 4}$ & $\mathbf{4}$ & $\mathbf{7}$ & $\mathbf{8 7 4}$ \\
\hline
\end{tabular}

Inv.-Involuntary, LTFU-Lost to follow up, TO- Transferred out, UDS-Urine Drug Screen, Vol.-Voluntary.

\section{Sociodemographic factors and cannabis use at repeat urine drug screen}

Table 6 shows the association between sociodemographic factors and cannabis use at repeat urine drug screen. University education was a significant factor associated with no cannabis use during follow up. Sub-analysis was done to assess for any difference between cannabis use only and cannabis and other substance use compared with no cannabis use. There was no 
significant association between cannabis use and other sociodemographic factors. Table 7 and 8 are attached as supplementary material.

Table 6: Sociodemographic factors and cannabis use at repeat urine drug screen (RUDS)

\begin{tabular}{|c|c|c|c|c|}
\hline \multicolumn{5}{|c|}{ Cannabis at RUDS, n (\%) } \\
\hline Age (Years) & Yes $(n=548)$ & No $(n=326)$ & OR $(95 \% \mathrm{CI})$ & p-value \\
\hline $18-27$ & $140(25.5)$ & $38(11.7)$ & $1.8(0.2-20.9)$ & 0.622 \\
\hline $28-37$ & $227(41.4)$ & $127(39)$ & $0.9(0.1-9.9)$ & 0.927 \\
\hline $38-47$ & $145(26.5)$ & $126(38.7)$ & $0.6(0.1-6.4)$ & 0.653 \\
\hline $48-57$ & $27(4.9)$ & $29(8.9)$ & $0.5(0.1-5.4)$ & 0.542 \\
\hline $58-67$ & $7(1.3)$ & $5(1.5)$ & $0.7(0.1-10.0)$ & 0.793 \\
\hline $68+$ & $2(0.4)$ & $1(0.3)$ & Reference & \\
\hline \multicolumn{5}{|l|}{ Gender } \\
\hline Male & $484(88.3)$ & $287(88.0)$ & $1.0(0.7-1.6)$ & 0.900 \\
\hline Female & $64(11.7)$ & $39(12.0)$ & Reference & \\
\hline \multicolumn{5}{|l|}{ Education } \\
\hline Primary & $284(51.8)$ & $165(50.6)$ & $0.9(0.3-2.6)$ & 0.787 \\
\hline Secondary & $208(38.0)$ & $124(38.0)$ & $0.8(0.3-2.5)$ & 0.753 \\
\hline Tertiary & $44(8.0)$ & $24(7.4)$ & $0.9(0.3-3.0)$ & 0.885 \\
\hline University & $2(0.4)$ & $8(2.5)$ & $0.1(0.02-0.8)$ & 0.031 \\
\hline None & $10(1.8)$ & $5(1.5)$ & Reference & \\
\hline \multicolumn{5}{|l|}{ Marital status } \\
\hline Single & $144(26.3)$ & $83(25.5)$ & $1.6(0.6-4.0)$ & 0.353 \\
\hline Married & $142(25.9)$ & $62(19.0)$ & $2.1(0.8-5.3)$ & 0.135 \\
\hline Divorced/Separated & $252(46.0)$ & $172(52.8)$ & $1.3(0.5-3.3)$ & 0.556 \\
\hline Widowed & $10(1.8)$ & $9(2.8)$ & Reference & \\
\hline \multicolumn{5}{|l|}{ Employment } \\
\hline Employed & $92(16.8)$ & $62(19.0)$ & $0.9(0.6-1.3)$ & 0.480 \\
\hline Business & $39(7.1)$ & $17(5.2)$ & $1.4(0.8-2.5)$ & 0.309 \\
\hline Unemployed & $417(76.1)$ & $247(75.8)$ & Reference & \\
\hline
\end{tabular}




\section{Discussion}

This study aimed to determine the prevalence and pattern of cannabis use and associated sociodemographic characteristics among patients receiving MMT. The findings show a high prevalence of cannabis use among the patients both at baseline and at follow up.

\section{Prevalence and pattern of cannabis use}

At intake prevalence of cannabis use was $85.8 \%$ which is similar to a study in South Africa that reported a prevalence of $87.3 \%$ at baseline (20) but higher than patterns recorded at baseline among patients getting enrolled in MMT in studies done in Canada $(17,28)$. A systematic review on cannabis use during pharmacological treatment for opioid use disorder showed a prevalence of $12-67 \%$ with a median of $23 \%(16)$. While this finding may reflect the difference in pattern of substance use in the different regions, it can also be influenced by different ways in which cannabis use is assessed, for example, some studies use self-report while in our study we used urine drug screen results to report on the prevalence.

During follow up, the prevalence of cannabis use was $62.7 \%$ which was high but lower than the prevalence during intake. Prevalence of cannabis use during OST varies in different regions and is consistent with similar studies done in the rest of the world which have reported a rate of $46.9-73 . \%(18-20,26)$ with one systematic review reporting a cumulative prevalence of $58 \%$ with a range between $28-79 \%$ (16). Continued use of cannabis during MMT is associated with negative effects such as high attrition, increased risk for psychiatry comorbidity and increased use of other substances $(15,24)$ and can be used as a proxy measure for poor treatment outcomes (37). This shows need for continued monitoring of cannabis use during MMT and providing relevant interventions for co-occurring cannabis use including psychosocial treatments such as 
cognitive behaviour therapy, motivational interviews and contingency management to improve treatment outcomes (37-39).

A pattern of polysubstance use in combination with cannabis was observed at baseline and during follow up with the most common substances used being cannabis, benzodiazepines and opioids. This pattern of polysubstance use is common among patients on MMT with one study in Finland reporting polysubstance use in $85 \%$ of patients (40) and in general population whereby cannabis use disorder is associated with lifetime use of all classes of drugs (41). This polysubstance use may arise due to several reasons such as genetic and environmental factors, use of specific combination of substances to get synergistic effects (24) or self-medication for withdrawal or negative emotional symptoms (37). This highlights the need to incorporate treatment for other substance use with OST for optimum care, which can include pharmacological treatment where applicable, psychological treatment and social support (42).

Whilst majority of those using cannabis at follow up were using cannabis at baseline, half of patients with no cannabis use at baseline started to use during follow up whereby the percentage of females was higher than males although this difference was not statistically significant. A similar pattern of initiating substance use during MMT follow up has been reported in a study in South Africa whereby alcohol use was found to increase in the initial period following MMT enrolment (43). This could imply that patients use cannabis use to manage withdrawal symptoms as reported in some studies $(26,27)$ although this finding has been disputed in another study (44). However, further research is needed to better explain this phenomenon.

Regarding cannabis use pattern and treatment retention, cannabis use was significantly associated with loss to follow up during MMT. In a systematic review that identified other substance use as a factor that influences retention in OST, the authors suggested need to assess 
the reasons for dropping out of treatment since voluntary and involuntary discontinuation may arise from different factors which if identified and addressed may improve treatment outcome (45). However, treatment retention may be related to several factors which we did not assess in this study. In one study that had a relapse rate of $76.6 \%$, the authors used decision tree analysis and identified five factors that influenced treatment retention including low cost of substances, early substance use onset, frequency of substance use, stopping substance use with no medication and frequency of MMT (46).

\section{Association of sociodemographic characteristics and cannabis use}

Similar to findings in previous studies, majority of those with cannabis use were males but there was no statistical difference in gender when comparing those using cannabis and cannabis non-users. Earlier reports have shown some gender differences among those using cannabis use during MMT. For example, cannabis use by females on MMT predicts continued illicit drug use, increased risk to develop cannabis use disorder and worse mental health outcomes compared to men (18) and impacts negatively to retention in treatment (17). This may be attributed to the gender differences among people with cannabis use disorder $(47,48)$.

Our study observed a low level of education among the majority, a finding similar to what was observed in regional studies in Tanzania $(33,34)$ and other parts of the world $(19)$. This may reflect the poor education attainment associated with cannabis use (49,50). University education was associated with reduced odds for using cannabis during follow up. Higher education may positively influence substance use behaviour through factors such as enhanced self-efficacy (46). A study in France among patients on MMT found that, low educational level was associated with increased cannabis use daily (51). Alternatively, the association between 
cannabis use and poor educational achievement could be due to a reverse causal association whereby poor educational achievement leads to increased cannabis use (49).

This study findings differ from other studies whereby we did not observe any significant association between age, employment and marital status with continued cannabis use during MMT as reported previously $(18,19,52)$. This may have arisen due to differences in study design and settings which can influence the outcomes. These include, difference in cannabis use assessment with some studies relying on self-report and others on urine toxicology results $(15,16,30)$; different studies do not differentiate the reason for cannabis use whether problematic use in cannabis use disorder or for recreational use which may influence outcome whereby problematic cannabis use is associated with poor patient outcomes $(15,16)$; influence of the age of onset of cannabis use, dosage and type of cannabis used, frequency of use, geographic location $(53)$ and psychiatric comorbidity $(21,54)$.

\section{Limitations}

This was a cross-sectional study which relied on retrospective abstraction of data hence not able to conclude on association between the exposure and outcome. Secondly, our study relied on record of urine drug screen and hence did not assess for use of other substances which were not measured by the screening tool such as alcohol, nicotine or khat. In addition, this study looked at cannabis based use on urine drug screen, which has variable length on time when positive compared to self-report and hence may not be a direct reflection of cannabis use in the study population.

\section{Conclusion}

To our knowledge, this is the first study to determine prevalence of cannabis use among patients receiving methadone in a clinic in Kenya. There is a high prevalence of cannabis use with 
pattern of polysubstance. In addition, cannabis use was associated with loss to follow up while university education reduced the odds of using cannabis. These findings are important in providing guidance on what to include in MMT programs. Continued screening and monitoring of cannabis use among patients on MMT may be important in identifying those using cannabis and then offer appropriate and targeted interventions to improve treatment outcomes.

To build upon our study findings, we recommend further studies to assess cannabis use among patients on MMT in other regions for comparison of findings. There is need for future research to involve longitudinal studies assessing the outcomes based on different patterns of cannabis as well as to explore the drivers for cannabis use individuals on MMT and effective interventions for cannabis use in our setting. These findings maybe used to inform policies on treatment of persons with opioid use disorder.

\section{List of abbreviation}

HIV- Human immunodeficiency virus

IQR - Interquartile range

Inv. - Involuntary

LTFU- Lost to follow up

MMT- Methadone maintenance treatment

MNTRH- Mathari National Teaching and Referral Hospital

OR- Odds ratio

OST- Opioid substitution therapy

RUDS- Repeat Urine Drug Screen 
SD- Standard deviation

SPSS - Statistical Package for the Social Sciences

TO- Transferred out

UDS- Urine drug screen

Vol. - voluntary

\section{Declarations}

\section{Ethics approval and consent to participate}

The study was performed in accordance with the Declaration of Helsinki. Ethical approval to conduct this study from Scientific Ethics and Research Committee of University of Nairobi, Kenyatta National Hospital (KNH-UON ERC) was obtained before conducting the study (approval number P313/04/2019). In addition, permission was sought to carry out the study from the management of MNTRH and the MMT clinic.

This was a retrospective study, involving data abstraction from patient records, with no direct interviews to patient, hence no consent to participate was required.

\section{Consent for publication}

Not applicable.

\section{Availability of data and materials}

Data sets used and analyzed in this current study are available from the corresponding author on reasonable request.

\section{Competing interests}

The authors declare that they have no competing interests.

\section{Funding}


The authors report no external funding for this study.

\section{Authors' contributions}

EWN was involved in study conception, design, acquisition and interpretation of data and drafting and revising the manuscript. SKK was involved in interpretation of data, drafting and revising of the manuscript. FRO and $\mathrm{RN}$ were involved in design, interpretation of data and revising the manuscript. All the authors read and approved the final version of the manuscript for publication.

Acknowledgements.

Not applicable. 


\section{References}

1. UNODC, Crime UNO on D and. World Drug Report 2020: Drug use and health consequences. United Nations publication, Sales No. E.20.XI.6. 2020.

2. Collins C. Adverse health effects of marijuana use. N Engl J Med. 2014;371(9):879.

3. Hoch E, Bonnetn U, Thomasius R, Ganzer F, Havemann-Reinecke U, Preuss UW. Risks associated with the non-medicinal use of cannabis. Dtsch Arztebl Int. 2015 Apr;112(16):271-8.

4. Degenhardt L, Ferrari AJ, Calabria B, Hall WD, Norman RE, McGrath J, et al. The global epidemiology and contribution of cannabis use and dependence to the global burden of disease: results from the GBD 2010 study. PLoS One. 2013;8(10):e76635.

5. Hosseini S, Oremus M. The Effect of Age of Initiation of Cannabis Use on Psychosis, Depression, and Anxiety among Youth under 25 Years. Can J Psychiatry. 2019 May;64(5):304-12.

6. Kurth AE, Cherutich P, Conover R, Chhun N, Bruce RD, Lambdin BH. The Opioid Epidemic in Africa And Its Impact. Curr Addict reports. 2018 Dec;5(4):428-53.

7. NACADA. National Survey on Alcohol and Drug Abuse Among Secondary School. $2016 ; 1-6$.

8. NACADA. Rapid Situation Assessment of Drugs and Substance Abuse in Kenya. NACADA Rep [Internet]. 2017;1(1):1-119. Available from: http://nacada.go.ke/?page_id=387\#

9. Kiburi SK, Molebatsi K, Obondo A, Kuria MW. Adverse childhood experiences among patients with substance use disorders at a referral psychiatric hospital in Kenya. BMC Psychiatry [Internet]. 2018 Jun 18;18(1):1-12. Available from: https://ukzn.idm.oclc.org/login?url=http://search.ebscohost.com/login.aspx?direct=true $\& \mathrm{db}=$ psyh \&AN=2018-29879-001\&site $=$ ehost-live \&scope $=$ site 
10. Razzaghi EM. A warm welcome to the diagnostic and statistical manual of mental disorders, fifth edition? Vol. 8, Iranian Journal of Psychiatry and Behavioral Sciences. 2014. 1-4 p.

11. Ad GD. 基因的改变NIH Public Access. Bone. 2008;23(1):1-7.

12. Larney S, Peacock A, Leung J, Colledge S. Global, regional, and country-level coverage of interventions to prevent and manage HIV and hepatitis $\mathrm{C}$ among people who inject drugs: A systematic review. 2017;(October).

13. Degenhardt L, Grebely J, Stone J, Hickman M, Vickerman P, Marshall BDL, et al. Series Drug Use 1 Global patterns of opioid use and dependence : harms to populations, interventions, and future action. Lancet [Internet]. 2019;394(10208):1560-79. Available from: http://dx.doi.org/10.1016/S0140$6736(19) 32229-9$

14. Ayanga D, Shorter D, Kosten TR. Update on pharmacotherapy for treatment of opioid use disorder. Expert Opin Pharmacother [Internet]. 2016;17(17):2307-18. Available from: http://dx.doi.org/10.1080/14656566.2016.1244529

15. Ming X, Mbbs Z, Marsh DC, Thabane L, Mbchb ZS. Cannabis use during methadone maintenance treatment for opioid use disorder: a systematic review and meta-analysis. $2019 ; 7(4)$

16. Lake S, St. Pierre M. The relationship between cannabis use and patient outcomes in medication-based treatment of opioid use disorder: A systematic review. Clin Psychol Rev [Internet]. 2020;82(March):101939. Available from: https://doi.org/10.1016/j.cpr.2020.101939

17. Franklyn AM, Eibl JK, Gauthier GJ, Marsh DC. The impact of cannabis use on patients enrolled in opioid agonist therapy in Ontario, Canada. PLoS One. 2017;12(11):1-11. 
18. Zielinski L, Bhatt M, Sanger N, Plater C, Worster A, Varenbut M, et al. Association between cannabis use and methadone maintenance treatment outcomes: an investigation into sex differences. Biol Sex Differ. 2017;8(1):1-10.

19. Bawor M, Dennis BB, Varenbut M, Daiter J, Marsh DC, Plater C, et al. Sex differences in substance use, health, and social functioning among opioid users receiving methadone treatment: A multicenter cohort study. Biol Sex Differ [Internet]. 2015;6(1):1-11. Available from: http://dx.doi.org/10.1186/s13293-015-0038-6

20. Morgan N, Daniels W, Subramaney U. A prospective observational study of heroin users in Johannesburg, South Africa : Assessing psychiatric comorbidities and treatment outcomes §. Compr Psychiatry [Internet]. 2019;95:152137. Available from: https://doi.org/10.1016/j.comppsych.2019.152137

21. Kidorf M, Disney ER, King VL, Neufeld K, Beilenson PL, Brooner RK. Prevalence of psychiatric and substance use disorders in opioid abusers in a community syringe exchange program. 2004;74:115-22.

22. Teoh J, Fei B, Yee A, Hussain M, Habil B. Psychiatric Comorbidity Among Patients on Methadone Maintenance Therapy and Its In fl uence on Quality of Life. 2016;4955.

23. Epstein DH, Preston KL, Epstein DH. Does Cannabis Use Predict Poor Outcome for Heroin-Dependent Patients on Maintenance Treatment? A Review of Past Findings, and More Evidence Against NIH Public Access. Bickel \& Amass. 1993;98(3):269-79.

24. Shams I, Sanger N, Bhatt M, Rosic T, Luo C, Shahid H, et al. The association between health conditions and cannabis use in patients with opioid use disorder receiving methadone maintenance treatment. BJPsych Open. 2019;5(6):1-8.

25. Bagra I, Krishnan V, Rao R, Agrawal A. Does Cannabis Use Influence Opioid Outcomes and Quality of Life Among Buprenorphine Maintained Patients? A Cross- 
sectional, Comparative Study. J Addict Med. 2018;12(4):315-20.

26. Scavone JL, Sterling RC, Weinstein SP, Van Bockstaele EJ. Impact of cannabis use during stabilization on methadone maintenance treatment. Am J Addict. $2013 ; 22(4): 344-51$

27. Kral AH, Wenger L, Novak SP, Chu D, Corsi KF, Coffa D, et al. Is cannabis use associated with less opioid use among people who inject drugs? Drug Alcohol Depend [Internet]. 2015;153:236-41. Available from: http://dx.doi.org/10.1016/j.drugalcdep.2015.05.014

28. Socías ME, Wood E, Lake S, Nolan S, Fairbairn N, Hayashi K, et al. High-intensity cannabis use is associated with retention in opioid agonist treatment: a longitudinal analysis. Addiction. 2018;113(12):2250-8.

29. Wiese B, Wilson-Poe AR. Emerging evidence for cannabis' role in opioid use disorder. Cannabis Cannabinoid Res. 2018;3(1):179-89.

30. Suzuki J, Weiss RD. Cannabinoids for the Treatment of Opioid Use Disorder: Where is the Evidence? J Addict Med. 2021;15(2):91-2.

31. Scheibe A, Marks M, Shelly S, Gerardy T, Domingo AK, Hugo J. Developing an advocacy agenda for increasing access to opioid substitution therapy as part of comprehensive services for people who use drugs in south africa. South African Med J. 2018;108(10):800-2.

32. International Harm Reduction. Global State of Harm Reduction: 2019 updates. Harm Reduct Int [Internet]. 2019;(November 2019):1-63. Available from: https://www.hri.global/global-state-of-harm-reduction-2019

33. Lambdin BH, Masao F, Chang O, Kaduri P, Mbwambo J, Magimba A, et al. Methadone treatment for HIV prevention- Feasibility, retention, and predictors of attrition in Dar es Salaam, Tanzania: A Retrospective cohort study. Clin Infect Dis. 
2014;59(5):735-42.

34. Das C Hansen KC and Tyler JK LMS. 乳鼠心肌提取 HHS Public Access. Physiol Behav. 2017;176(3):139-48.

35. Guise A, Ndimbii J, Igonya EK, Owiti F, Strathdee SA, Rhodes T. Integrated and differentiated methadone and HIV care for people who use drugs: a qualitative study in Kenya with implications for implementation science. Heal Policy Plan [Internet]. 2019 Mar;34(2):110-9. Available from:

https://ukzn.idm.oclc.org/login?url=http://search.ebscohost.com/login.aspx?direct=true $\& \mathrm{db}=\mathrm{c} 8 \mathrm{~h} \& \mathrm{AN}=136101865 \&$ site $=$ ehost-live $\&$ scope $=$ site

36. Rhodes T, Guise A, Ndimbii J, Strathdee S, Ngugi E, Platt L, et al. Is the promise of methadone Kenya's solution to managing HIV and addiction? A mixed-method mathematical modelling and qualitative study. BMJ Open. 2015;5(3).

37. White WL, Campbell MD, Spencer RD, Hoffman HA, Crissman B, DuPont RL. Patterns of Abstinence or Continued Drug Use Among Methadone Maintenance Patients and Their Relation to Treatment Retention. J Psychoactive Drugs [Internet]. 2014;46(2):114-22. Available from: http://dx.doi.org/10.1080/02791072.2014.901587

38. Hoch E, Preuss W, Ferri M. Digital Interventions for Problematic Cannabis Users in Non-Clinical Settings : Findings from a Systematic Review and Meta-Analysis. $2016 ; 233-42$.

39. Le Foll B, Sabioni P. Psychosocial and pharmacological interventions for the treatment of cannabis use disorder. F1000Research. 2018;7(0):1-8.

40. Heikman PK, Muhonen LH, Ojanperä IA. Polydrug abuse among opioid maintenance treatment patients is related to inadequate dose of maintenance treatment medicine. BMC Psychiatry. 2017;17(1):1-11.

41. Hayley AC, Stough C, Downey LA. DSM-5 cannabis use disorder, substance use and 
DSM-5 speci fi c substance-use disorders : Evaluating comorbidity in a populationbased sample. Eur Neuropsychopharmacol [Internet]. 2017;27(8):732-43. Available from: http://dx.doi.org/10.1016/j.euroneuro.2017.06.004

42. Carlsen SL, Lunde L. Opioid and Polydrug Use Among Patients in Opioid Maintenance Treatment. 2020;9-18.

43. Subramaney U. An Inverse Relationship Between Alcohol and Heroin Use in Heroin Users Post Detoxi fi cation. 2020;1-8.

44. Epstein AJ, Barry CL, Fiellin DA, Busch SH. Patient valuation of different approaches to mental health and substance use disorder treatment. Value Heal [Internet]. 2015;18(3):A277. Available from: https:/www.cochranelibrary.com/central/doi/10.1002/central/CN-01088926/full

45. Malcolm CP, Picchioni MM, DiForti M, Sugranyes G, Cooke E, Joseph C, et al. Premorbid Conduct Disorder symptoms are associated with cannabis use among individuals with a first episode of psychosis. Schizophr Res [Internet]. 2011 Mar;126(1-3):81-6. Available from: https://ukzn.idm.oclc.org/login?url=http://search.ebscohost.com/login.aspx?direct=true $\& \mathrm{db}=\mathrm{ccm} \& \mathrm{AN}=104835207 \&$ site $=$ ehost-live $\&$ scope $=$ site

46. Moradinazar M, Farnia V, Alikhani M, Karyani AK, Rezaei S, Rezaeian S, et al. No Title. 2020;35(1).

47. Greaves L, Hemsing N. Sex and gender interactions on the use and impact of recreational cannabis. Int J Environ Res Public Health. 2020;17(2):1-15.

48. Sheean et al. 2013. 基因的改变NIH Public Access. Bone. 2008;23(1):1-7.

49. Horwood LJ, Fergusson DM, Hayatbakhsh MR, Najman JM, Coffey C, Patton GC, et al. Cannabis use and educational achievement: Findings from three Australasian cohort studies. Drug Alcohol Depend [Internet]. 2010;110(3):247-53. Available from: 
http://dx.doi.org/10.1016/j.drugalcdep.2010.03.008

50. Thompson K, Leadbeater B, Ames M, Merrin GJ. Associations Between Marijuana Use Trajectories and Educational and Occupational Success in Young Adulthood. Prev Sci. 2019;20(2):257-69.

51. Mayet A, Lions C, Roux P, Mora M, Maradan G, Morel A, et al. Variations in Cannabis Use Level and Correlates in Opiate-Users on Methadone Maintenance Treatment: A French Prospective Study. J Subst Abuse Treat [Internet]. 2015;58:1005. Available from: http://dx.doi.org/10.1016/j.jsat.2015.06.015

52. Choi NG, DiNitto DM, Marti CN. Marijuana use among adults: Initiation, return to use, and continued use versus quitting over a one-year follow-up period. Drug Alcohol Depend [Internet]. 2018;182(September 2017):19-26. Available from: https://doi.org/10.1016/j.drugalcdep.2017.10.006

53. Rosic T, Kapoor R, Panesar B, Naji L, Chai DB, Sanger N, et al. The association between cannabis use and outcome in pharmacological treatment for opioid use disorder. Harm Reduct J [Internet]. 2021;18(1):1-9. Available from: https://doi.org/10.1186/s12954-021-00468-6

54. Yang M, Liao Y, Wang Q, Chawarski MC, Hao W, Province H, et al. HHS Public Access. 2015;272-9. 


\section{Supplementary Files}

This is a list of supplementary files associated with this preprint. Click to download.

- SUPPLEMENTARYMATERIAL.pdf 